\title{
Mechanical Properties of Sisal Fiber Reinforced with Basalt and Glass Fiber for Composite Application
}

\author{
Gowtam J K, Raju BR, Naveen Kumar R, Sanjay H M
}

\begin{abstract}
In a present development world materials will be made up of light weight, better strength, easily availability and low cost ie. Composite materials are Automotive application, aerospace application, marine, construction and household purposes. In this paper we research a natural fiber ie. Sisal and basalt fiber, we can use also glass fiber. Numerous specialist made on these fiber however we can utilize sisal+basalt+epoxy, sisal+glass+epoxy, glass+basalt+epoxy, sisal+epoxy, basalt+epoxy, glass+epoxy by made on Hand layup followed by vacuum bag technique for contrasting the mechanical properties like ductile, flexural and sway quality which is better one for including filler material in next advancement venture Sisal fiber any place on the planet is effectively accessible for automobile application, agricultural application and etc. so on at low coast, basalt fiber is likewise less expensive contrasted with carbon fiber, better warm safe and these to filaments are biodegradable can makes these blend for improves the properties of composite material.
\end{abstract}

Keywords : Composite material, Basalt fiber, Epoxy, Glass fiber and Sisal fiber

\section{INTRODUCTION} comprises of at least 2 segments working along to supply material properties that are totally unique to the properties of these components all alone. In follow, most composites incorporate a mass material (the 'grid'), and a support or some likeness thereof, valuable essentially to expand the quality and solidness of the lattice. This support is once in a while in fiber kind. Today, the preeminent basic incredible composites are frequently separated into 3 fundamental gatherings:

Revised Manuscript Received on February 05, 2020.

* Correspondence Author

Mr. Gowtam J K*,Associate Professor, Department of Mechanical engineering, PES institute of technology and management, Shimoga-577204 Karnataka, India, gowtam@pestrust.edu.in

Dr. Raju B R, Associate Professor, Department of Automobile engineering, the oxford college of engineering, Bangalore -560068, Karnataka India, rajusrujan@gmail.com

Mr. Naveen Kumar R, student M.tech in Machine Design, SJBIT, Bangalore, Karnataka, India nvnkmr206@gmail.com

Mr. Sanjay H M, Assistant professor, Department of Mechanical engineering, Sapthagiri College of engineering, Bangalore- 560057, Karnataka, India hmsanjayhsd@gmail.com

(c) The Authors. Published by Blue Eyes Intelligence Engineering and Sciences Publication (BEIESP). This is an open access article under the CC BY-NC-ND license (http://creativecommons.org/licenses/by-nc-nd/4.0/)
In its most straightforward kind a stuff is one, that

Polymer Matrix Composites (PMC's) - These are the main typical and can be dis-stiff-necked here. moreover called FRP - Fiber bolstered Polymers (or Plastics) - these materials use a polymer-based rosin considering the way that the structure, and a spread of strands like glass, carbon and aramid considering the way that the stronghold.

Metal Matrix Composites (MMC's) - progressively found inside the vehicle trade, these materials use a metal like atomic number 13 because the structure, and fortify it with strands, or particles, like carbide.

Aesthetic Matrix Composites (CMC's) - Used in awfully hot temperature circumstances, these materials use a terminated considering the way that the system and sustain it with short fibers, or stubbles like those made up of carbide and $\mathrm{B}$ engineered compound.

\section{MATERIALS AND METHODS;}

A. SISAL FIBER: Sisal fiber mats are made of natural fibres get from sisal plant that possess terribly sturdy properties, creating a wonderful quality mat. Sisal mats are infamous for his or her strength. As hostile some artificial mats, Sisal mats last for much longer and still manage to take care of that current look.

Sisal tangles likewise are earth well disposed, they're spun from present sisal filaments that are gathered ordinarily p.a. also, don't hurt the setting. the different hues, styles, weaves, and mixes are the makings of an irksome determination, as each is as dazzling on the grounds that the following.

In case you're attempting to discover huge amounts of steadiness in your Sisal Mat you may wish to go with a fiber blend. On the off chance that you might want that unmistakable tropical look, you may wish to mull over going with a sea grass weave. there's a scope of weaves, and each idea off an unmistakable environment. a few of the mats might be tweaked; you'll have the option to arrange explicit sizes that meet your wants.

B. BASALT FIBER: Basalt is standard as rock found in pretty much every nation round the world. Its principle use is as a stone used in development, modern and street building. yet, it's not unremarkably better-realized that volcanic stone are frequently used in delivering and made into fine, superfine and ultrafine strands. Included single fixing staple mollify, volcanic stone strands are better than various filaments as far as warm dependability, warmth and sound protection properties, vibration obstruction and strength.

Basalt persistent filaments give absolutely new change of composite materials and item.

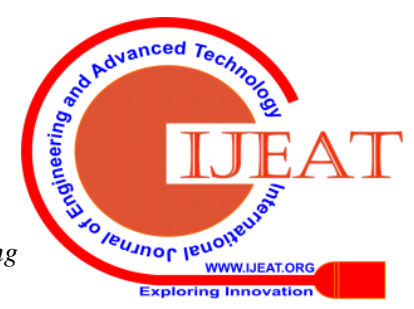


since it is eminent, volcanic stone is that the name given to a scope of molten stone renowned mainly for its protection from high temperatures, quality and toughness, wide unobtrusive all round the world,

inside which $\mathrm{SiO}$ represents the most half, trailed by kind basalts fulfill the conditions for fiber planning.

As a matter of fact volcanic stone likewise can be formed into endless fiber having particular compound and mechanical properties, so it's unmistakably fit to hard-to-satisfy applications requiring obstruction against high temperatures, protection properties, corrosive and dissolvable opposition, solidness, mechanical quality, tide assimilation, and so forth.

C. GLASS FIBER: Fiberglass alludes to a gaggle of item made up of individual glass strands consolidated into a scope of structures. Glass strands may be partioned into 2 huge gatherings relentless with their geometry: ceaseless fibers used in yarns and materials, and thus the sporadic (short)fibers used as batts, covers or sheets for insurance and filtration. Fiberglass will be framed into yarn on a very basic level equivalent to wool or cotton, and plain-woven into material that is typically used for draperies. covering material materials are regularly used as a fortress material for confined and overlaid plastics. covering material wool, a thick, down like material made up of unpredictable fibers, is used for warm insurance and sound maintenance. It is commonly found in ship and submarine bulkheads and structures;engine compartments

and body board liners; in radiators and air con units; material science divider and rooftop sheets; and field of study portions.

Planning OF LAMINATES: Laminates are prepared by hand b-ball shot strategy followed by sack procedure beginning cut the fiber into 220x220 metric direct unit measurement for preparing tractable, flexural and sway example for in step with ASTM principles. when cutting the filaments, wax are fixed for higher than referenced measurement for non-clingy then spot a fiber glue an epoxy and again a zone a fiber cover sort. the resulting subtleties contain what extent layer is put during a fiber for preparing a plates.

Table 1.1 shows a composition with layer laminating

\begin{tabular}{|c|c|c|}
\hline Sl. No. & Composition & Layers \\
\hline I & Sisal + epoxy & $\mathrm{S}+\mathrm{S}+\mathrm{S}+\mathrm{S}+\mathrm{S}+\mathrm{S}$ \\
\hline II & Basalt + epoxy & $\mathrm{B}+\mathrm{B}+\mathrm{B}+\mathrm{B}+\mathrm{B}+\mathrm{B}+\mathrm{B}+\mathrm{B}+\mathrm{B}+\mathrm{B}$ \\
\hline III & Glass + epoxy & $\mathrm{G}+\mathrm{G}+\mathrm{G}+\mathrm{G}+\mathrm{G}+\mathrm{G}$ \\
\hline IV & Sisal + Basalt+ epoxy & $\mathrm{S}+\mathrm{S}+\mathrm{S}+\mathrm{B}+\mathrm{B}+\mathrm{B}+\mathrm{B}$ \\
\hline V & Sisal + Glass + epoxy & $\mathrm{S}+\mathrm{S}+\mathrm{S}+\mathrm{G}+\mathrm{G}+\mathrm{G}$ \\
\hline VI & Glass + Basalt +epoxy & $\mathrm{G}+\mathrm{G}+\mathrm{G}+\mathrm{G}+\mathrm{B}+\mathrm{B}+\mathrm{B}+\mathrm{B}+\mathrm{B}$ \\
\hline
\end{tabular}

\section{RESULTS \& DISCUSSION:}

A. Tensile test: Tensile test will be done by in step with ASTM standard D638 with a removal speed of two $\mathrm{mm} / \mathrm{min}$. Gauge length of $125 \mathrm{~mm}$, specimen length $165 \mathrm{~mm}$, thickness of three metric linear unit and capability of $\mathrm{Al} 2 \mathrm{O} 3$, at that point $\mathrm{Fe} 2 \mathrm{O} 3, \mathrm{FeO}, \mathrm{CaO}$ and exclusively acidic

machine is $10 \mathrm{KN}$ the subsequent fig. shows the before fracture and after fracture of specimen.

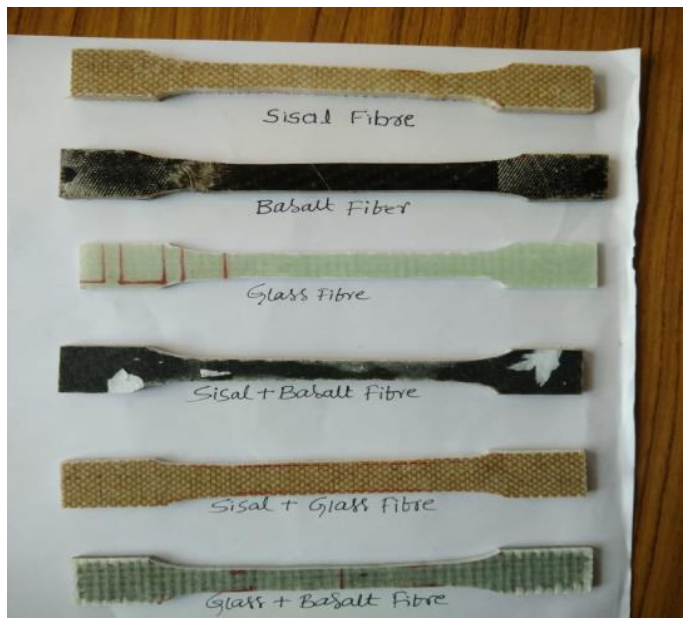

Fig.1 Shows Tensile specimen before fracture

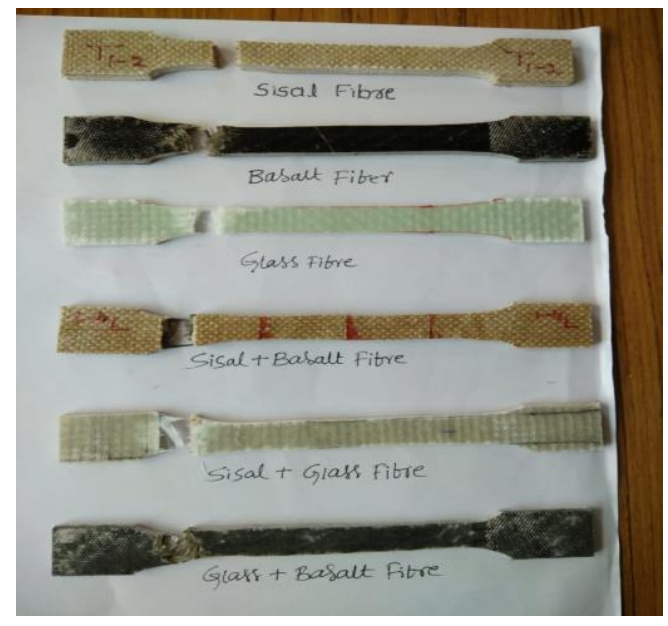

Fig.2 Shows Tensile specimen after fracture

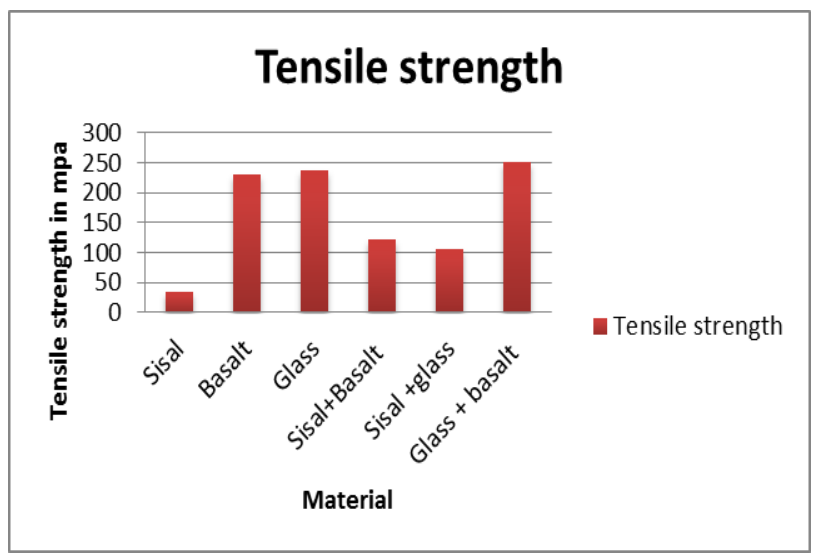

Fig.3 Shows Tensile strength of the specimens

The fig. shows the bar chart of tensile strength it clearly shows that sisal fiber has a minimum tensile strength of $35.071 \mathrm{~N} / \mathrm{mm}^{2}$, maximum tensile strength has Glass+Basalt fiber of $251.842 \mathrm{~N} / \mathrm{mm}^{2}$.

B. Flexural test : This test can be carried out by according to ASTM standard D698 has dimension of specimen is 90X13X3mm as shown in fig. before and after fracture of specimen. 


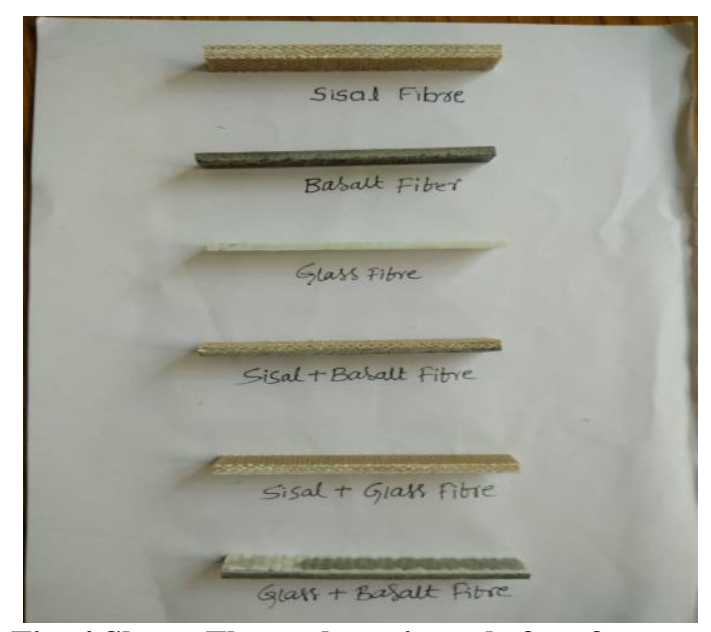

Fig. 4 Shows Flexural specimen before fracture

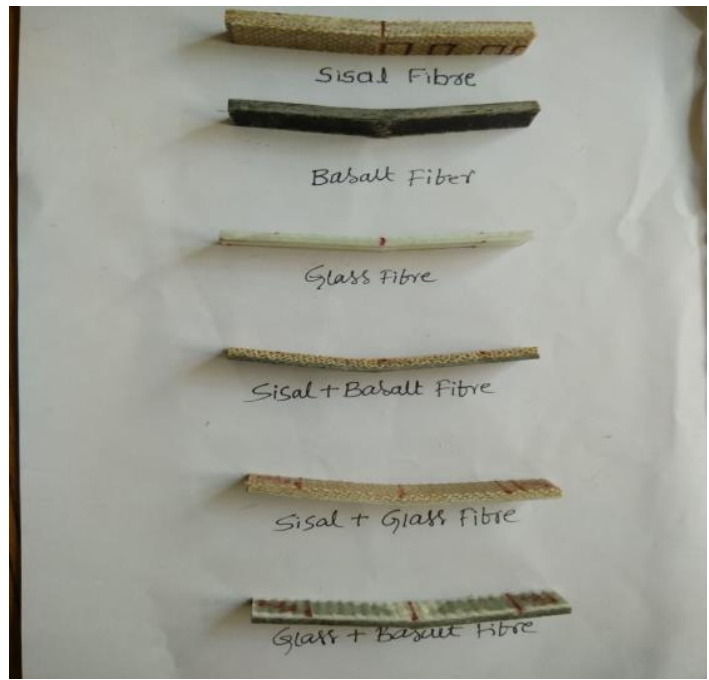

Fig.5 Shows Flexural specimen after fracture

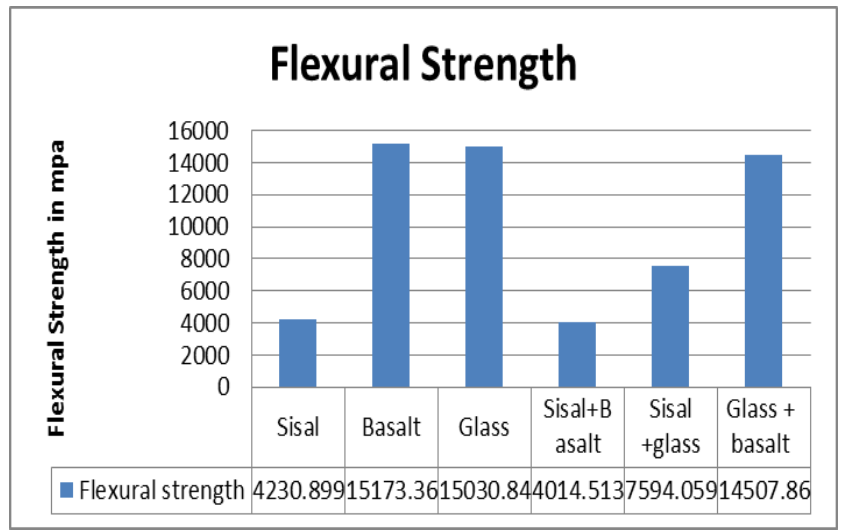

Fig.6 Shows Flexural strength of the specimens

In this fig. clearly shows that sisal +basalt has minimum flexural strength of $4014.513 \mathrm{~N} / \mathrm{mm}^{2}$ and maximum flexural strength has Glass fiber of $15030.84 \mathrm{~N} / \mathrm{mm}^{2}$.

C. Impact test: Effect test is mechanical test used to measure the impact obstruction of the material for the unexpected burden. Effect test did by as per the ASTM standard D 256. With a component of 60X13X3mm as appeared in figure underneath when break of example.

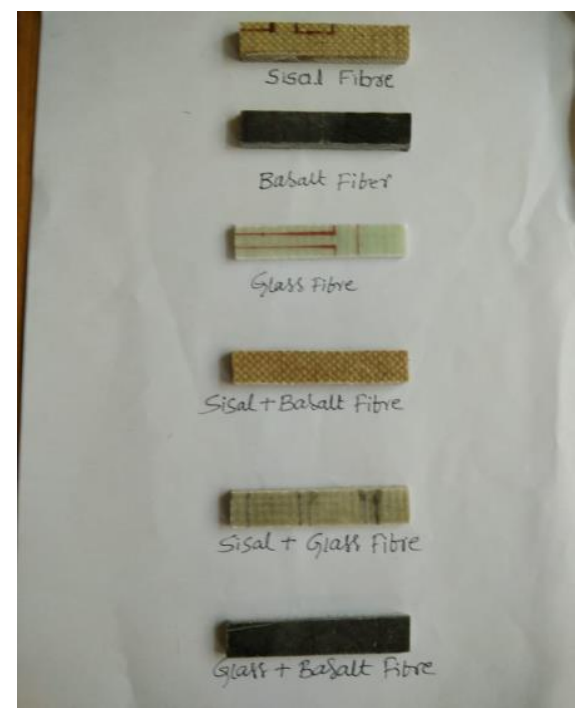

Fig.7 Shows Impact specimen before fracture

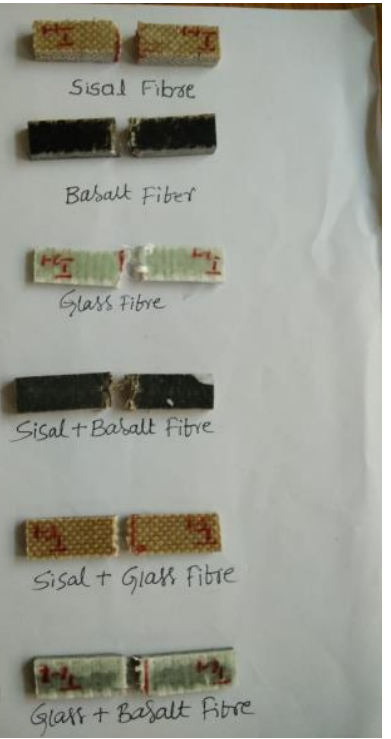

Fig.8 Shows Impact specimen after fracture

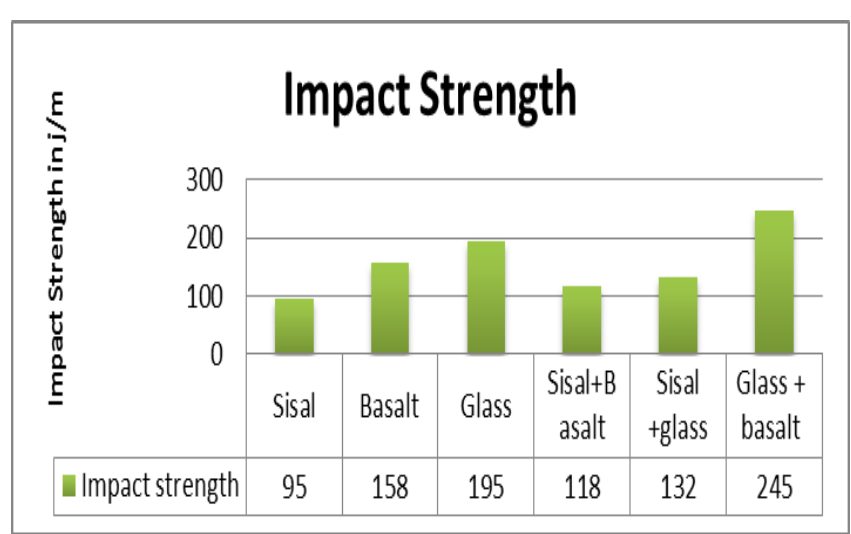

Fig.9 Shows Impact strength of the specimens

Fig.9 clearly shows that Glass + Basalt fiber has maximum impact strength of $245 \mathrm{~N} / \mathrm{mm}^{2}$ compared to other fiber shows and sisal fiber has minimum impact strength of $95 \mathrm{~N} / \mathrm{mm}^{2}$.

Published By:

Blue Eyes Intelligence Engineering 


\section{SEM ANALYSIS}

Fig. 10 shows SEM images of Sisal fiber

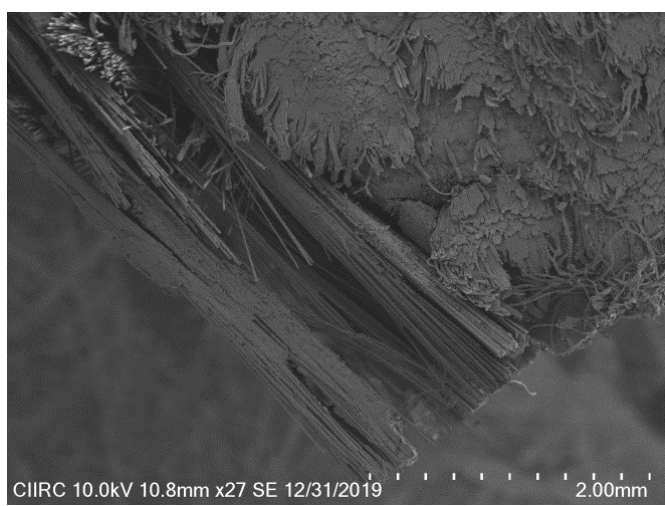

Fig. 11 shows SEM images of Basalt fiber

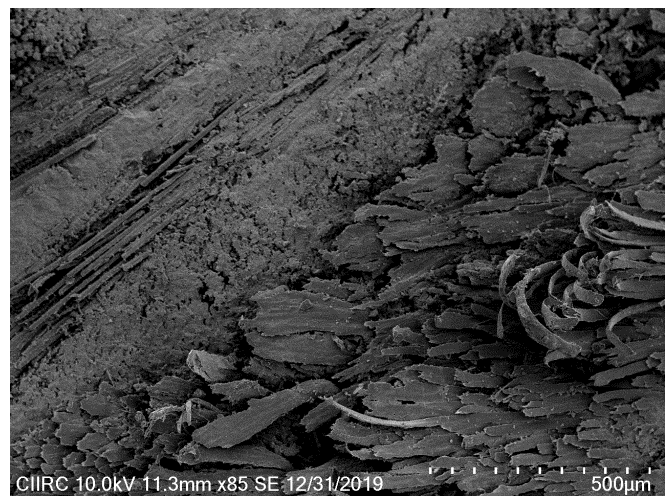

Fig. 12 shows SEM images of Sisal+Basalt fiber

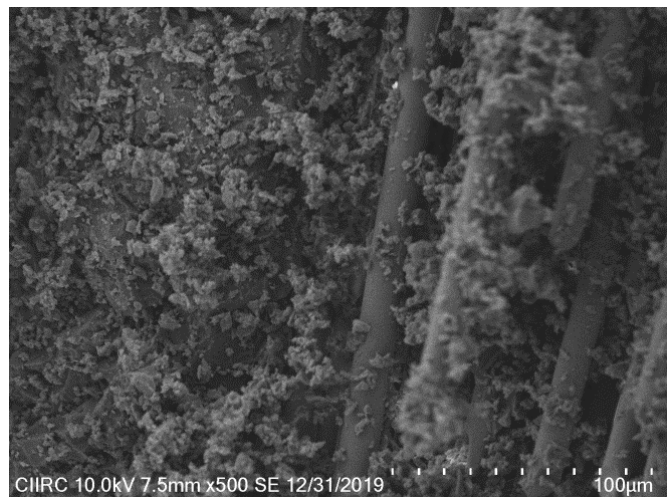

Fig. 13 shows SEM images of Sisal+Glass fiber

Fig.10 shows the SEM pictures of Tensile example on sisal fiber, during this fiber is fallback, there's no holding between the strands. Fig.11 shows the SEM pictures of volcanic rock fiber it's there's bonding between the fibers and has strength is most. Fig.12 shows the SEM pictures of Sisal+

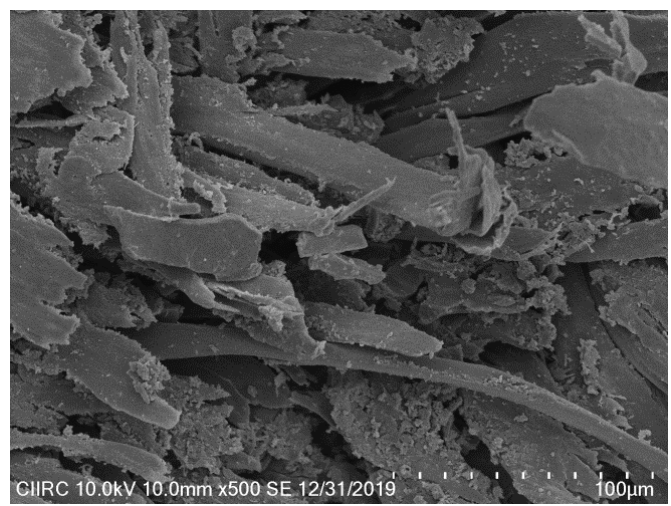

volcanic rock fiber, during this bonding is no bit between the fiber shows minimum strength and same continue within the Fig. 13. i.e is SEM pictures of Sisal+ glass fibre.

\section{CONCLUSION:}

1. The tensile strength of the sisal fiber has minimum with a value of $35.071 \mathrm{~N} / \mathrm{mm}^{2}$ and maximum of Glass + Basalt fiber has $251.842 \mathrm{~N} / \mathrm{mm}^{2}$ of all the conducted above combinations.

2. The flexural strength of sisal fiber has minimum with a value of $4230.899 \mathrm{~N} / \mathrm{mm}^{2}$ and maximum of Basalt fiber has $15173.36 \mathrm{~N} / \mathrm{mm}^{2}$.

3. The impact strength of sisal fiber has minimum with a value of $95 \mathrm{~J} / \mathrm{min}$. and maximum of Glass + Basalt fiber has $245 \mathrm{~J} / \mathrm{min}$.

4. The SEM analysis Studied the clear picture of the sisal fiber and mixed with other combinations.

\section{REFERENCES}

1. Goulart S.A.S., Oliveira T.A., Teixeira A., Mileo P.C., Mulinari D.R. Mechanical behaviour of polypropylene reinforced palm fibers composites, Procedia Engineering;2011;10:2034-2039.

2. Flavio de Andrade Silva, Romildo Dias Toledo Filho, Joao de Almeida MeloFilho, Eduardo de Moraes Rego Fairbairn, Physical and mechanical properties of durable sisal fiber-cement composites, Construction and Building Materials;2010;24:777785.

3. K.Sabeel Ahmed and S.Vijayarangan, Tensile, flexural and interlaminar shear properties of woven jute and jute-glass fabric reinforced polyester composites,Material Processing Technology;2008;207:330-335.

4. Maries Idicula, S.K. Malhotra, Kuruvilla Joseph, Sabu Thomas, Dynamic mechanical analysis of randomly oriented intimately mixed short banana/sisal hybrid fiber reinforced polyester composites, Composites

Science and Technology;2005;65: 1077-1087.

5. K.Sabeel Ahmed, S. Vijayarangan, A.C.B. Naidu, Elastic properties, notched strength and fracture criterionin untreated woven jute-glass fabric reinforced polyester hybrid composites, Materials and Design;2007;28:2287 2294.

6. Yan Li, Yiu-Wing Mai, Lin Ye, Sisal fiber and its composites: A review of recent developments, Composites science and technology;2000;60:2037-2055.

7. M. Jawaid , H.P.S. Abdul Khalil, A. Abu Bakar, P. NoorunnisaKhanam, Chemical resistance, void content and tensile properties of oil palm/jute fiber reinforced polymer hybrid composites, Materials and Design;2011;12: 1014-1019.

8. M. Jawaid, H.P.S. Abdul Khalil, Azman Hassan, Rudi Dungani, A. Hadiyane, Effect of jute fibre loading on tensile and dynamic mechanical properties of oil palm epoxy composites.

9. KasamaJarukumjorn, NitinatSuppakarn, Effect of glass fiber hybridization on properties of sisal fiber polypropylene composites, Composites: Part B;2009;40:623627.

10. Maries Idicula, S.K. Malhotra, Kuruvilla Joseph, Sabu Thomas, Dynamic mechanical analysis of randomly oriented intimately mixed short banana/sisal hybrid fiber reinforced polyester composites, Composites Science and Technology; 2005;65:1077 1087.

11. N. Venkateshwaran, A. Elayaperumal, G.K. Sathiya, Prediction of tensile properties of hybrid-natural fiber composites,Composites:Part B;2012;43:793796.

12. K. Murali Mohan Rao, K. Mohana Rao, A.V. Ratna Prasad, Fabrication and testing of natural fiber composites: Vakka, sisal, bamboo and banana, Materials and Design ;2010;31: 508513.

13. N. Venkateshwaran, A. ElayaPerumal, A. Alavudeen, M. Thiruchitrambalam, Mechanical and water absorption behaviour of banana/sisal reinforced hybrid composites, Materials and Design;2011;32:40174021.

14. BledzkiAK,GassanJ.Compositesreinforced with cellulose based.bres. ProgPolymSci 1999;24:221-74.

Published By:

Blue Eyes Intelligence Engineering 
15. Mwaikambo LY, Ansell MP. Chemical modi.cation of hemp, sisal,jute, and kapok .bers by alkalisation. J ApplPolymSci 2002;84(12):2222-34. 3.

16. JochenGassan. A study of .bre and interface parameters a.ectingthe fatigue behavior of natural.brecomposites. Composites Part A: 2002;33(3):369-74. 4.

17. Ruys D, Crosky A, Evans WJ. Natural bast .bre structure.Int J Mater Product Technol 2002;17(1-2):2-10.

18. Mishra S, Tripathy SS, Misra M, Mohanty AK, Nayak SK. Novel ecofriendly biocomposites: bio.berrein forced biodegradable polyester amide composites - fabrication and properties evaluation. J ReinfPlastComp 2002;21(1):55-70.

\section{AUTHORS PROFILE}

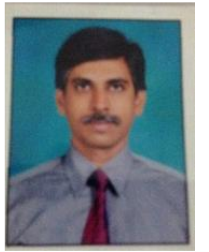

Mr. Gowtam J K, Research Scholor \& Associate Professor Department of Mechanical Engineering, PES Institute of Technology \& Management NH-206, Sagar Road, Shimoga-577204 (Karnataka)

Contact

No:

9980193104

E-mail: gowtam@pestrust.edu.in

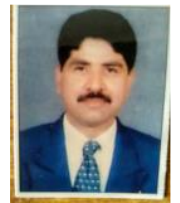

Dr. Raju B R, Professor, Department of Automobile Engineering, The Oxford College of Engineering Banglore - 560068 Contact no: 9448373636 Email: rajusrujan@gmail.com

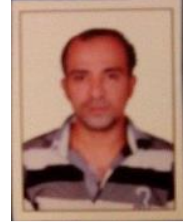

Mr. Naveen Kumar R, Student, M.tech in Machine design SJBIT,

Banglore - 560068 Contact No. 9611432164 Email: nvnkmr206@gmail.com

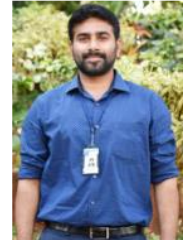

Mr. Sanjay H M, Assistant Professor, Dept. of Mechanical Engineering,

Sapthagiri College of Engineering, Chikkasandra Bangalore - 560057

Contact no. $9611118987 \quad$ Email:

hmsanjayhsd@gmail.com 